\title{
A perceção dos enfermeiros pediátricos sobre a importância dos avós no hospital
}

The perception of pediatric nurses about the importance of grandparents in the hospital

\section{Eliana Rocha}

Hospital Professor Doutor Fernando Fonseca, E.P.E.

eliana.m.oliveira.rocha@gmail.com 


\section{RESUMO}

A hospitalização de uma criança é um momento gerador de stress em toda a família, pelo que os profissionais de saúde não devem descurar uma avaliação cuidada acerca da mesma.

Realizou-se um estudo com abordagem quantitativa e qualitativa, através da aplicação de um questionário, disponibilizado nas redes sociais, e de uma observação participada, no sentido de perceber a perceção dos enfermeiros sobre a importância da visita dos avós no hospital quando uma criança está internada.

Participaram 57 enfermeiros, sendo que todos consideraram a visita dos avós importante, tendo mesmo $71,9 \%$ avaliado que as visitas dos avós são importantes na maioria das vezes.

A visita dos avós proporciona momentos de descanso para os pais, bem como de apoio aos mesmos e reveste-se de extrema importância na relação de cumplicidade e afeto com os netos.

Palavras-Chave: criança, avós, família, hospitalização, enfermeiros

\section{ABSTRACT}

The hospitalization of a child is a stressful moment in the whole family, so health professionals should not neglect a careful assessment of it.

A study with a quantitative and qualitative approach was carried out, through the application of a questionnaire, made available on social networks, and a participatory observation, to understand the perception of nurses about the importance of visiting grandparents in hospital when a child is hospitalized.

Fifty-seven nurses participated, all of whom considered the visit of grandparents important, and $71,9 \%$ of them assessed that the visits are important most of the time.

The visit of grandparents provides moments of rest for parents, as well as support for them and is extremely important in the relationship of complicity and affection with grandchildren.

Keywords: children, grandparents, family, hospitalization, nurse 


\section{INTRODUÇÃO}

A hospitalização de uma criança é sempre vivenciada como um momento de crise para a família. Exige por si só uma readaptação de toda a dinâmica familiar, para além de geradora de stress e ansiedade em todos os elementos da família.

Para a criança, representa medos e anseios, relacionados com o desconhecido, ambiente e profissionais, com a separação dos pais e com a própria dor, de acordo com a sua faixa etária.

Nestes momentos, a família desempenha um papel preponderante no equilíbrio e bemestar daquela criança. Os avós têm, na maioria das vezes, um papel fundamental na sua vida (Brazelton, 2006, p.483).

\section{ENQUADRAMENTO}

Quando falamos em hospitalização, isso implica uma rutura com as rotinas e hábitos diários da criança, sendo que muitas estão diretamente relacionadas com o papel desempenhado pelos avós nas suas vidas. São eles que muitas vezes substituem os pais nas tarefas diárias, por causa da vida profissional, pessoal ou recreativa destes, bem como são os que, muitas vezes, transmitem segurança e conforto para a criança.

Assim, em contexto de hospitalização, os profissionais devem estar atentos à dinâmica da família e perceber qual o papel/importância que os avós desempenham na vida da criança e no seio da família. São muitas vezes a força que suporta e mantém os outros membros da família, sendo necessário que os profissionais de saúde reconheçam a importância dos avós e os integrem no processo de cuidados (Martins \& Ramos, 2020, p.290).

Num estudo realizado no Brasil, com avós de crianças com cancro hospitalizadas, estes consideraram que a sua função neste contexto seria "ser o alicerce da família" (Dias \& Mendes-Castillo, 2021, p.1), transmitir amor, estar presente e oferecer suporte espiritual para o filho e neto, bem como conseguir gerir os seus próprios sentimentos e manter 0 equilíbrio da família com os recursos disponíveis.

Também, Moraes \& Mendes-Castillo (2018), referem que os avós desempenham um importante papel no apoio à família durante momentos de crise, como é a hospitalização de um neto. Os mesmos autores, ressalvam, no entanto, a preocupação que os 
profissionais devem ter com o sofrimento vivenciado pelos avós, uma vez que estes sobrepõem, muitas vezes, as necessidades da restante família em detrimento do seu sofrimento.

Percebemos por tudo o que foi dito até ao momento, a importância de incluir os avós na intervenção dos profissionais à criança, enquanto parceiros de cuidados.

Enquanto enfermeira especialista em Saúde Infantil e Pediátrica, e através da observação participada na investigação, numa abordagem etnográfica (Bryman, 2012) verificamos que o papel do enfermeiro na área pediátrica prende-se com o bem-estar da criança em qualquer fase da sua vida, sendo que é muito importante envolver as pessoas que são significativas no seu desenvolvimento e, neste caso, a importância dos avós.

Foi com esta motivação que se estabeleceu o objetivo deste estudo, que se centrou na recolha de opinião e na análise sobre a perceção dos enfermeiros que exercem funções em serviços de pediatria em relação à presença dos avós no hospital.

\section{METODOLOGIA}

Elaborou-se um questionário com sete $(\mathrm{N}=7)$ questões, quatro $(\mathrm{N}=4)$ das quais perguntas abertas, disseminando-se via online, através das redes sociais como o Facebook, WhatsApp, Instagram e Linkedln, no período de 1 a 15 de novembro de 2021.

Este questionário destinou-se a enfermeiros a exercer funções em serviços de pediatria (crianças dos 0-18 anos).

Assim, através deste estudo, pretendeu-se elaborar uma análise dos dados e uma reflexão crítica sobre a perceção dos enfermeiros acerca da importância dos avós no acompanhamento das crianças (dos 0-18 anos) quando estão internadas no hospital.

Obtiveram-se 57 respostas.

As questões colocadas foram as seguintes: 
Quadro 1 - Questões abordadas no questionário aos enfermeiros pediátricos:

1. Sou enfermeiro(a) num serviço de pediatria há:

2. Sou enfermeiro(a) especialista de saúde infantil e pediátrica?

3. No serviço onde trabalha, são permitidas as visitas dos avós?

4. Considera que as visitas dos avós são importantes para as crianças, quando estão internadas?

4.1. Se respondeu afirmativamente à questão anterior, por favor descreva em que aspetos considera que essa presença no hospital/clínica, é ou seria fundamental?

4.2. Com que regularidade considera que seria positiva a presença dos avós?

4.3. Se respondeu negativamente, diga-nos 2 razões.

5. Da sua experiência, quando os avós não visitam as crianças quando estão internadas é porque (pode escolher até 2 respostas):

6. Que tipo de conversas e ações observa que são desenvolvidas pelos avós quando visitam 0 seu neto(a) no hospital/clínica? (pode escolher mais do que uma intervenção)

6.1. Se escolheu a $1^{\mathrm{a}}$ ou a $2^{\mathrm{a}}$ resposta na pergunta anterior diga-nos quais as conversas ou as histórias que já teve oportunidade de testemunhar na sua prática.

7. Tem mais alguma informação que gostaria de relatar sobre a importância da presença e acompanhamento dos avós a crianças em situação de internamento?

Fonte: Elaboração própria

\section{RESULTADOS}

Todos os participantes deram o seu consentimento para participar neste estudo.

A maioria dos participantes $(35,1 \%)$ exercem funções como enfermeiros num serviço de pediatria entre 10 e 20 anos, sendo que $31,6 \%$ há mais de 20 anos.

Um total de $59,6 \%$ dos enfermeiros são especialistas em saúde infantil e pediátrica.

Em 78,9\% dos serviços onde os participantes trabalham são permitidas as visitas dos avós às crianças quando estão internadas.

Do total dos respondentes, $71,9 \%$ consideram que as visitas dos avós "são importantes" na maioria das vezes, sendo que os restantes referem que "por vezes são". Não existiram respostas negativas em relação a esta questão.

Os resultados apontam também para os seguintes dados relativos às razões subjacentes sobre a importância visitas dos avós são importantes para as crianças quando estão internadas, que podem ser observadas no quadro 2. 
Quadro 2 - Razões sobre a importância da visita dos avós a crianças internadas

- Dão suporte emocional aos pais;

- Diminui 0 impacto da hospitalização (aumenta segurança e diminui os medos)

- Muitas vezes são os cuidadores principais das crianças; são pessoas de referência

- Participação no processo terapêutico

- Permite humanizar 0 ambiente hospitalar, tornando-o mais familiar

- Permitem manter a ligação emocional e os elos familiares, contribuindo para o bem-estar emocional e psicológico

- Permitem substituir os pais, permitindo-Ihes tempo para descanso e para outros afazeres;

- Presença fundamental na recuperação da criança

- Transmitem segurança às crianças

Fonte: Elaboração própria

A maioria dos enfermeiros que participaram neste estudo $(66,7 \%)$ consideram que as visitas dos avós não deveria ter horário definido.

Entre as razões apontadas sobre a falta de visita ou ausência dos avós nos hospitais, destacam-se os seguintes: 1) quando a situação clínica da criança não permite $(24,6 \%)$ ou, 2) quando as horas da visita não são conciliáveis com a vida profissional/afazeres dos avós $(17,5 \%)$.

As principais atividades desenvolvidas pelos avós quando visitam as crianças no hospital podem observar-se no quadro 3.

Quadro 3 - Principais atividades desenvolvidas pelos avós

- Trazem livros ou outros objetos que são significativos para a criança $(63,2 \%)$;

- Contam histórias que a criança gosta $(36,8 \%)$.

- Conversam sobre assuntos que a criança gosta $(52,6 \%)$;

- Trazem comida $(\mathbf{5 7 , 9 \% )}$;

Fonte: Elaboração própria

Em relação aos temas das conversas e histórias que os enfermeiros tiveram oportunidade de testemunhar ao longo da sua vida profissional, destacam-se no Quadro 4. 
Quadro 4. - Temas das conversas e histórias entre avós e crianças no hospital

\begin{tabular}{ll}
\hline \multicolumn{1}{c}{ HISTÓRIAS } & \multicolumn{1}{c}{ CONVERSAS } \\
\hline Tradicionais & Brincadeiras fora do hospital \\
\hline De encantar & Amigos da escola \\
\hline Disney & Futebol \\
\hline Sobre animais de estimação & Animais de estimação \\
\hline Princesas & Experiências semelhantes à que a criança está a passar \\
\hline Carros & O quanto gostam dos netos \\
\hline Desenhos animados & Família que está em casa \\
\hline Sobre as próprias crianças & Fazem planos conjuntos para quando sair do hospital \\
\hline De quando os avós eram crianças & Atividades que a criança gosta \\
\hline & Desenhos animados que a criança gosta \\
\hline & Passeios \\
\hline & Cozinhados \\
\hline & Escola \\
\hline & Coisas positivas \\
\hline & Sobre a paixão que mais os une \\
\hline
\end{tabular}

Fonte: Elaboração própria

Entre os comentários elaborados pelos enfermeiros nas perguntas abertas podem ainda ser considerados pelos enfermeiros outros aspetos importantes referidos no Quadro 5.

Quadro 5 - Emoções e Expressões sobre a importância dos avós:

\begin{tabular}{|c|c|}
\hline Emoções e atitudes & Expressões \\
\hline $\begin{array}{l}\text { Calma } \\
\text { Experiência }\end{array}$ & $\begin{array}{l}\text { Os avós são mais calmos e mais experientes a lidar com a situação de } \\
\text { hospitalização da criança; }\end{array}$ \\
\hline $\begin{array}{l}\text { Controlo } \\
\text { Preparação antecipatória } \\
\text { do encontro }\end{array}$ & $\begin{array}{l}\text { É importante a preparação dos avós antes das visitas para o que vão } \\
\text { encontrar - ajuda a diminuir o impacto visual. }\end{array}$ \\
\hline Cuidado e atenção & São pessoas "significativas e de referência para os netos". \\
\hline $\begin{array}{l}\text { Grau de proximidade } \\
\text { efetivo }\end{array}$ & $\begin{array}{l}\text { Fazem parte da educação e rotinas diárias da criança. Passam muito } \\
\text { tempo com elas. } \\
\text { São muitas vezes os cuidadores principais. } \\
\text { Nem sempre a visita dos avós é benéfica. É importante avaliar o grau de } \\
\text { ligação/importância é que os avós têm para a criança e na dinâmica } \\
\text { familiar (relação com os pais). }\end{array}$ \\
\hline $\begin{array}{l}\text { Sentido de pertença } \\
\text { Identidade de grupo }\end{array}$ & $\begin{array}{l}\text { Como me disse uma menina de } 5 \text { anos quando lhe perguntei quem era } \\
\text { aquele grupo enorme à janela do quarto: "são as minhas pessoas" com } \\
\text { as duas mãos encostadas ao peito." }\end{array}$ \\
\hline Bem-estar & $\begin{array}{l}\text { Pode "auxiliar no processo de recuperação" e ser crucial na "resolução da } \\
\text { situação". } \\
\text { Ajuda no bem-estar e tranquilidade da criança. }\end{array}$ \\
\hline $\begin{array}{l}\text { Positividade } \\
\text { Afetividade }\end{array}$ & $\begin{array}{l}\text { A visita dos avós permite à criança abstrair-se dos aspetos negativos da } \\
\text { doença e hospitalização. } \\
\text { As crianças "ficam muito contentes", pois os "avós estão sempre } \\
\text { disponíveis para brincar" e são uma "mais-valia no conforto e segurança". } \\
\text { Os avós são "cúmplices dos netos", há troca de "afetos e abraços", "dão } \\
\text { muitos beijos"; "aconchegam, mimam". }\end{array}$ \\
\hline
\end{tabular}


"O amor que os avós transmitem é fortalecedor."

Familiaridade Possibilita que as crianças se "sintam em casa" e permite "humanizar mais

o ambiente hospitalar", tal como tornar a experiência "mais acolhedora e

menos traumática".

Torna o ambiente mais familiar, diminuindo o impacto da hospitalização, bem como tranquiliza a criança face ao desconhecido.

Resiliência É fundamental "na gestão do stress da criança".

Fonte: Elaboração própria

\section{DISCUSSÃO}

Os resultados obtidos neste estudo, foram congruentes com o encontrado na literatura (Dias \& Mendes-Castillo, 2021; Moraes \& Mendes-Castillo, 2018; Wakefield et al., 2014).

A importância dos avós durante o internamento dos netos é reconhecida não só pelos próprios, mas também pelos profissionais de saúde, neste caso pelos enfermeiros de pediatria.

A presença dos avós representa, por um lado, apoio para a criança e pais na gestão do seu dia e rotinas, por outro traduz-se em segurança e amor, envolvendo toda a família.

A relação entre avós e netos é vista como única e, na maioria das vezes, traz benefícios para a criança, incluindo à sua recuperação.

No contexto de internamento, os avós levam brinquedos e objetos significativos para a criança e comida, contam histórias e conversam com a criança. Deste modo, tentam manter alguns dos hábitos diários e familiares, bem como os afetos da relação já vinculada.

No entanto, é de ressalvar que também os avós vivem um momento de sofrimento e que deverão ser preparados para as visitas às crianças, sendo que os profissionais devem estar atentos e dar resposta também às necessidades destes elementos da família.

Importante também ter em consideração que a visita dos avós poderá não beneficiar a criança ou os pais, quando a relação existente entre eles é fraca ou conflituosa previamente. Mais uma vez, torna-se essencial uma avaliação adequada da família. 


\section{CONCLUSÃO}

Os avós, como parte integrante da família, são elementos essenciais na vida das crianças, pelo que as visitas por eles quando as crianças estão internadas, revela-se na maioria das vezes fundamental. Este facto foi amplamente reconhecido pelos enfermeiros que participaram neste estudo.

Os benefícios das visitas dos avós às crianças internadas são mútuos, no que respeita ao bem-estar e à manutenção da saúde mental, bem como no fortalecimento da relação existente.

Os avós pela sua experiência de vida, conseguem, por um lado, apoiar os pais e, por outro, distrair e satisfazer as necessidades da criança.

Este estudo teve algumas limitações por ser exploratório, com um número reduzido de respondentes. Neste sentido deve ampliar-se a investigação nesta área que tem vindo a ganhar mais peso entre a investigação na saúde e que se prende com o bem-estar e 0 benefício de estratégias, como a conexão familiar e social entre a criança internada e a sua família e o mundo exterior, que contribuem para que a vida no hospital tenha mais conforto para todos os envolvidos.

\section{AGRADECIMENTOS}

Agradeço à Professor Doutora Cristina Vaz de Almeida a orientação dada no questionário e 0 apoio aos conteúdos agora apresentados. Agradeço a todos os enfermeiros pediátricos que responderam a este estudo, os contributos para esta investigação, que permite abrir alguma luz sobre esta temática. 


\section{BIBLIOGRAFIA}

Brazelton, T. B. (2006). 0 grande livro da criança - o desenvolvimento emocional e do comportamento durante os primeiros anos. Queluz de Baixo: Editorial Presença.

Bryman, A. (2012). Social research methods. NY: Oxford University Press.

Dias, L. B., \& Mendes-Castillo, A. M. C. (2021). 0 papel dos avós de crianças com câncer hospitalizadas. Revista Brasileira de Enfermagem, 74(5), 8. https://doi.org/10.1590/0034-7167

Martins, L., \& Ramos, S. (2020). A Criança e o Jovem em Fim de Vida. In A. L. Ramos \& M. do C. Barbieri-Figueiredo (Eds.), Enfermagem em Saúde da Criança e do Jovem (p. 325). Lidel.

Moraes, E. S., \& Mendes-Castillo, A. M. C. (2018). A experiência dos avós de crianças hospitalizadas em Unidade de Terapia Invasiva Pediátrica. Revista Da Escola de Enfermagem Da USP, 52(e03395), 8. https://doi.org/10.1590/S1980220X2017040003395

Wakefield, C. E., Drew, D., Ellis, S. J., Doolan, E. L., McLoone, J. K., \& Cohn, R. J. (2014). Grandparents of children with cancer: A controlled study of distress, support, and barriers to care. Psycho-Oncology, 23(8), 855-861. https://doi.org/10.1002/pon.3513 